\title{
Fornecimento de bens, serviços e mão de obra para o upstream da indústria petrolífera - histórico no Brasil e Medidas de Indução ao Desenvolvimento Econômico na Bahia
}

\author{
Regina Célia Palácio Lambiase*
}

\begin{abstract}
Resumo: Este artigo traça um histórico do fornecimento nacional de bens e serviços e mão de obra do upstream offshore da indústria petrolífera brasileira, e apresenta as medidas tomadas que de alguma maneira ajudam na indução ao fornecimento local no estado da Bahia. A história da indústria nacional de bens e serviços do upstream apresenta períodos de intensos desenvolvimento e outros de declínio transitório. Dessa maneira, para melhor visualização desses momentos, faz-se necessária uma revisão histórica dos fatos que desencadearam tal quadro econômico. E, num segundo momento, apresentar as iniciativas e propostas mais relevantes como meio de melhorar as dificuldades no fornecimento local de suprimentos para pequenas e médias operadoras de campos marginais, principalmente, no estado baiano.
\end{abstract}

Palavras-chave: Desenvolvimento econômico, petróleo, upstream, bens, serviços, mão de obra.

\footnotetext{
"Mestre profissional em Regulação da Indústria de Energia pela Universidade Salvador, UNIFACS. Endereço eletrônico: reginapalacio@gmail.com
} 


\section{Introdução}

$\mathrm{O}$ fornecimento de bens, serviços e mão de obra, destinados à exploração e à produção de petróleo e gás natural offshore no Brasil, ainda passa por intensas dificuldades, seja por falta de suprimentos em território nacional, seja por escassez de serviços adequados para atender ao setor, ou seja, por motivos de falta de comunicação entre o que se oferta e o que se necessita efetivamente no mercado, como é o caso da mão de obra especializada.

Muitas foram e são as iniciativas destinadas a sanar os problemas provenientes do fornecimento de suprimentos para o upstream da indústria petrolífera no país. Este artigo tem como objetivo apresentar essas iniciativas e o êxito de algumas delas. Além disso, pretende-se mostrar a necessidade de fortalecer a oferta nacional de bens, serviços e mão de obra especializados para o upstream offshore, sendo esta uma condição fundamental para o crescimento da indústria no Brasil.

Visto em escala nacional e comparando com outros países, o fornecimento de suprimentos, de maneira geral, teve significativo crescimento no Brasil, porém, muito mais se deve à entrada de empresas estrangeiras, do que à inserção de novas empresas nacionais ou do crescimento das mesmas. Iniciativas políticas e também de cunho econômico têm ganhado destaque nesse contexto.

Dessa forma, este artigo tem como objetivo principal traçar um histórico brasileiro de tentativas de fortalecimento do mercado de bens, serviços e recursos humanos para o upstream da indústria petrolífera no Brasil. Num segundo momento, pretende-se apresentar as iniciativas e propostas mais relevantes como meio de melhorar as dificuldades no fornecimento local de suprimentos para pequenas e médias operadoras de campos marginais, sobretudo, no estado da Bahia.

\section{Histórico e cenário atual}

A Petrobrás ao iniciar suas atividades no ano de 1954 dependia praticamente de $100 \%$ da importação de materiais, equipamentos, serviços e inclusive técnicos especializados. Com o objetivo de reduzir a dependência externa, a empresa realizou amplo esforço de capacitação de seus recursos humanos e desenvolvimento de tecnologias (Onip, 2005). Nesta fase, a estatal investiu em cursos para especialização do corpo técnico mediante parcerias com universidades, escolas técnicas e Senai (Serviço de Aprendizagem Industrial), além do envio de pessoal para cursos de capacitação no exterior, a fim de compor progressivamente seu quadro de funcionários. Em paralelo, a mesma passou também a apoiar, por meio de parcerias com empresas nacionais e internacionais, fornecedoras de materiais e equipamentos, o desenvolvimento industrial local, bem como a capacitação nacional de serviços especializados no setor petroleiro (Rappel, 2003).

A estratégia adotada nesse plano de nacionalização de bens e serviços foi bastante positiva para o país e, também, para a própria Petrobrás, sendo vários os benefícios sócio-econômicos alcançados. Dentre eles, destacam-se a capacitação nacional na indústria petroleira, bem como os ganhos substanciais obtidos em termos de geração de renda e criação de empregos especializados no mercado interno (Furtado e Fernandes, 2002). Salienta-se que, além dos pontos anteriormente destacados, a Petrobrás se tornou uma das companhias petrolíferas mais importantes do mundo graças à utilização de tecnologia, bens e serviços brasileiros.

A partir de 1979, a Petrobrás estimulou empresas nacionais a prestarem serviços offshore, utilizando equipamentos de perfuração próprios. Foram também estimuladas a prestarem serviços de perfuração onshore empresas de engenharia nacionais, porém utilizando equipamentos da própria Petrobrás (Folkerts, 2004).

O processo de abertura econômica que logo se seguiu, no início dos anos 90, o fim das barreiras não tarifárias à importação e a dificuldade de acesso a créditos competitivos agravaram ainda mais a situação dos fornecedores brasileiros de bens e serviços. Ainda nos anos de 1990, a Petrobrás alterou drasticamente sua política de compras no setor de upstream, cujas mudanças foram bastante significativas. Com a abertura desse segmento, em 1997, alguns blocos foram licitados para exploração e, com isso, cerca de quarenta novas empresas passaram a atuar no país. A queda marcante nos índices de compras de bens e serviços locais decorreram, sobretudo, da contratação de projetos de engenharias e construção por meio de empresas estrangeiras. Surge então um efeito natural de arraste de encomendas de bens e serviços a fornecedores externos, devido à diversas vantagens, tais como, tecnologia e mão de obra altamente qualificada. Além disso, a legislação tributária brasileira apresentava brecha que facilitava a importação de equipamentos adquiridos pela Petrobrás no exterior, sob regime de admissão temporária, uma vez que tal manobra isentava a estatal de tributos incidentes sobre bens importados (Imposto de Importação (II), Imposto sobre Produtos Industrializados (IPI) e Imposto sobre Circulação de Mercadorias e Serviços (ICMS) (Rappell, 2003). Tal cenário de redução de encomendas no mercado interno causou inúmeros prejuízos para o país, pois além de se perderem divisas com a importação de bens e serviços, deixava-se de gerar emprego, renda e arrecadação nas mediações das áreas de exploração e produção de petróleo e gás (Onip, 2005).

Tendo passado por forte crise, principalmente entre os anos de 1992 e 1993, os fornecedores nacionais começaram a se recuperar com o advento do Plano Real. Essa recuperação, entretanto, deu-se menos em função de uma política fiscal isonômica e estímulos fiscais do que da política cambial adotada (elevação do preço de produtos importados) (Folkerts, 2004).

Nesse novo contexto, foi criada a Agência Nacional de Petróleo, Gás Natural e Biocombustíveis (ANP), que é uma autarquia integrante da Administração Pública Federal, vinculada ao Ministério de Minas e Energia. Tem por finalidade promover a regulação, a contratação e a fiscalização das atividades econômicas integrantes da indústria do petróleo, de acordo com o estabelecido na Lei $\mathrm{n}^{\circ} 9.478$, de 06/08/97, regulamentada pelo Decreto $\mathrm{n}^{\circ}$ 
2.455, de 14/01/98, nas diretrizes emanadas do Conselho Nacional de Política Energética (CNPE) e em conformidade com os interesses do País (ANP, 2006).

Pouco após a criação da ANP, surgiu, em agosto de 1998, o movimento Compete Brasil, iniciativa do setor privado brasileiro para reverter o quadro de alienação dos fornecedores locais frente à estratégia adotada pela Petrobrás. Esse movimento reivindicava o aumento da competitividade da indústria nacional pela isonomia fiscal, criação de linhas de financiamento atrativas e estímulos à participação nos negócios de exploração e produção em suas futuras concorrentes (Folkerts, 2004).

Solidária aos acontecimentos e anseios do Movimento Compete Brasil, a ANP, em associação com a PUC-RJ, em 1999, promoveu um estudo com vistas a diagnosticar a competitividade da indústria nacional no suprimento local de bens e serviços no setor petrolífero. O trabalho se intitulou: "Mecanismos de Estímulo às Empresas Concessionárias de Petróleo a Adquirirem Equipamentos, Materiais e Serviços no Mercado Nacional". Como resultado, o estudo mostrou um índice de $60 \%$ da capacidade da indústria para atender a demanda por bens e serviços na construção de sistema de produção no mar, sem avaliar a capacidade instalada (Onip, 2003)

O diagnóstico apresentado gerou algumas sugestões para incentivar o parque supridor nacional. E, desde então, foram adotados diversos procedimentos com esse fim, entre eles, destacam-se a criação: do CT Petro (Plano Nacional de Ciência e Tecnologia do Setor Petróleo e Gás Natural); do PRH-ANP (Programa de Recursos Humanos - ANP) criado em 2000, com o propósito de contribuir no aumento da mão de obra especializada; e do Repetro (regime aduaneiro especial de exportação e de importação de bens destinados às atividades de pesquisa $\mathrm{e}$ de lavra das jazidas de petróleo e de gás natural).

O Plano Nacional de Ciência e Tecnologia do Setor Petróleo e Gás Natural (CTPetro) foi criado para fomentar a capacitação de pessoal e reduzir o gargalo tecnológico nacional existente. Nesse plano, a ANP transfere royalties adquiridos ao Ministério da Ciência e Tecnologia o qual transfere os recursos para o Fundo Nacional de Desenvolvimento Científico e Tecnológico (FNDCT), administrados pela FINEP, com a finalidade de celebrar convênios com universidades e centros de pesquisa. Nessa perspectiva, a Financiadora de Estudos e Projetos (FINEP) disponibiliza recursos por meio de editais que selecionarão projetos que apresentem conteúdo inovador e tecnológico ao setor Petróleo, sendo requisito básico que o projeto seja realizado em parceria com universidades ou centros de pesquisas nacionais. Essa exigência visa à interação formal entre setor privado e academia, o que gera aprendizado mútuo e, conseqüentemente, inovação tecnológica no País. Há ainda a obrigatoriedade de aplicação de 40\% dos recursos nas regiões Norte e Nordeste para descentralizar a capacitação técnico-científica no âmbito nacional (Rappel, 2003).

Ainda dentro dessa discussão, a ANP promoveu iniciativa para estimular a formação profissional através do Programa de Recursos Humanos para o Setor Petróleo e Gás (PRH-ANP). Nesse programa, a ANP concede, por intermédio das instituições de ensino conveniadas (principalmente universidades, CEFETs e SENAI), bolsas de estudo a alunos e professores e taxa de bancada, usando recursos do CTPetro para realização de cursos stricto sensu, com ênfase em áreas relacionadas à indústria do petróleo. Desde o lançamento do primeiro edital em 1999, foram firmados convênios com 36 instituições de nível superior e 8 de nível médio (DiagPetro, 2006).

Outros fatores importantes, destacados nesse estudo, foram as recomendações sobre o regime de admissão temporária de bens vigente na época que fossem empreendidas ações junto à Receita Federal para criação de instrumentos de desoneração tributária de equipamentos, peças e componentes incorporados em bens importados via admissão temporária. O regime aduaneiro especial para atividades petrolíferas no país, criado com a instituição do Repetro, veio incorporar muitas das sugestões do estudo realizado (Onip, 2005). O Repetro, instituído pelo decreto 3.161 de 02 de setembro de 1999, foi criado com a finalidade de garantir o equilíbrio tributário dos produtos nacionais frente aos importados (Lima, 2006). Cabe ressaltar que a expansão do setor petrolífero nos anos 90 se deu numa época de preços depreciados do petróleo no mercado internacional. Como a nova política nacional estava privilegiando a atração de investimentos externos para o setor, manifestou-se uma assimetria na instituição de instrumentos de política industrial, notadamente no que diz respeito à ampliação da lista de bens submetidos ao regime de admissão temporária. Desta forma, a instituição do regime de exportação no âmbito do Repetro poderia corrigir essa assimetria.

Paralelo às medidas adotadas, o BNDES instituiu em junho de 1999 o Programa de Apoio a Investimentos em Petróleo e Gás (PROGAP). Com ele, seria possível o financiamento de $100 \%$ dos gastos locais, limitados a $80 \%$ dos investimentos e a oferta de recursos de curto prazo (BNDES, 2000).

Em janeiro de 2003, foram realizados estudos com o objetivo de subsidiar a tomada de decisões para a alocação de recursos e definição de atividades estratégicas, no âmbito do CTpetro. Entre eles, destaca-se a Nota Técnica 05 (Política de Compras da Indústria de Petróleo e Gás Natural e a Capacitação dos Fornecedores no Brasil: o mercado de Equipamentos para o Desenvolvimento de Campos Marítimos), a qual evidenciou um déficit anual médio do setor petróleo em bens e serviços da ordem de US\$ 1,8 bilhão (Onip, 2005).

No mesmo ano, o Ministério de Minas e Energia lançou o PROMINP Programa de Mobilização da Indústria Nacional de Petróleo e Gás, com o objetivo de "maximizar a participação da indústria nacional de bens e serviços, em bases competitivas e sustentáveis, na implantação de projetos de óleo e gás no Brasil e no exterior" (Alvarenga e Fernández, 2003, p. 17).

Como incremento ao programa de estímulo ao adensamento da cadeia de suprimentos local, foram instituídos pela ANP editais de licitação para assegurar oportunidades de reintegração de fornecedores locais de bens e serviços no mercado da indústria petroleira, sendo que, já no primeiro Round de licitações, uma cláusula licitatória denominada de Conteúdo Local (CL) foi introduzida nos editais de licitações exploratórias da ANP. O conteúdo local é uma cota de aquisição de bens e serviços de fornecedores nacionais (Rappel, 
2003).

Para se traçar a evolução do CL no decorrer dos leilões e licitações da ANP, é de fundamental importância, inicialmente, apresentar os limites percentuais utilizados nos Editais de Licitações em cada rodada. Como pode ser visto no Quadro 1, até a quarta rodada de licitações não houve mudanças nas regras de percentuais de conteúdo local. Aliado a isso, vale destacar que até o round quatro, o peso desses percentuais foi de $15 \%$, cabendo ao Bônus Assinatura os $85 \%$ restantes para ganhar a concessão.

\begin{tabular}{|c|c|c|c|c|c|c|c|c|c|}
\hline \multirow{5}{*}{$\begin{array}{c}\text { Localização } \\
\text { do Blocos }\end{array}$} & \multirow{5}{*}{$\begin{array}{c}\text { Quadro } \\
\text { Percentual }\end{array}$} & \multirow{3}{*}{\multicolumn{2}{|c|}{ Rodadas 1a 4}} & \multirow{3}{*}{\multicolumn{2}{|c|}{ Rodadas 5 e 6}} & & 50 & & \\
\hline & & & & & & \multicolumn{4}{|c|}{ Rodadas 7} \\
\hline & & & & & & \multirow{2}{*}{\multicolumn{2}{|c|}{$\begin{array}{c}\text { Campos } \\
\text { Marginais } \\
\text { Etapas }\end{array}$}} & \multicolumn{2}{|c|}{$\begin{array}{c}\text { Campos } \\
\text { Exploratórios }\end{array}$} \\
\hline & & \multicolumn{2}{|c|}{ Etapas } & \multicolumn{2}{|c|}{ Etapas } & & & \multicolumn{2}{|c|}{ Etapas } \\
\hline & & Explor. & Desenv. & Explor. & Desenv. & Explor. & Desenv. & Explor. & Desenv \\
\hline \multirow{2}{*}{$\begin{array}{c}\text { Águas } \\
\text { Profundas }\end{array}$} & Máximo & $50 \%$ & $70 \%$ & & - & - & - & $55 \%$ & $65 \%$ \\
\hline & Mínimo & - & - & $30 \%$ & $30 \%$ & - & - & $37 \%$ & $55 \%$ \\
\hline \multirow{2}{*}{$\begin{array}{l}\text { Águas } \\
\text { Rasas }\end{array}$} & Máximo & $50 \%$ & $70 \%$ & - & - & - & - & $60 \%$ & $70 \%$ \\
\hline & Mínimo & - & - & $50 \%$ & $60 \%$ & - & - & $51 \%$ & $63 \%$ \\
\hline \multirow{2}{*}{ Terra } & Máximo & $50 \%$ & $70 \%$ & - & - & - & - & $80 \%$ & $85 \%$ \\
\hline & Mínimo & - & - & $70 \%$ & $70 \%$ & $70 \%$ & $70 \%$ & $70 \%$ & $77 \%$ \\
\hline
\end{tabular}

Fonte: Lima, 2006

No primeiro leilão, ocorrido em 1999, o índice de nacionalização da proposta foi de $15 \%$ da pontuação dos concorrentes e não houve exigência de participação mínima, mas o não cumprimento do índice ofertado resultou em multa. Por isso, apesar do percentual de comprometimento máximo situar-se em $50 \%$ na exploração e $70 \%$ no desenvolvimento, a participação de fornecedores locais, nas propostas vencedoras, atingiu apenas $25 \%$ e $27 \%$ respectivamente. No segundo round, no ano de 2000 , a participação de fornecedores locais nas propostas vencedoras ficou entre $30 \%$ a $70 \%$ nas fases de exploração e desenvolvimento, respectivamente. Apesar dos índices de aquisição máxima permanecerem os mesmos da rodada anterior, os percentuais de efetiva aquisição foram muito mais elevados. Com isso, abriu-se espaço para ações destinadas a incrementar a capacidade das empresas nacionais de atender a essas encomendas (BNDES, 2000).

Na terceira rodada de licitações, sucedida em 2001, percebeu-se uma queda substancial do índice de nacionalização das propostas. Essa queda, segundo a Onip (2005), pode ser atribuída à nova sistemática de avaliação dos serviços prestados no Brasil, introduzida pela ANP, quando se passou a considerar o valor agregado de materiais e serviços locais efetivamente incorporados aos mesmos. Outro fator causador da diminuição de aquisição local se deve à maior participação de blocos em mar na terceira rodada, comparada à segunda. E, por fim, a última explicação para a queda seria a entrada de novos operadores, que, por não estarem familiarizados com o ambiente institucional e econômico brasileiro, teriam mais cautela com esse tipo de comprometimento. Uma ocorrência de destaque, do terceiro round, é que a capacidade média de atendimento do fornecedor nacional caiu para $28,4 \%$ na etapa de exploração e para $39 \%$ na fase de desenvolvimento, quando na rodada anterior, foi de $42 \%$ e $48 \%$ respectivamente. Do ponto de vista da atração de investimentos, não existem controvérsias quanto ao sucesso das três rodadas de licitações, porém, o problema maior foi o relativo à capacidade de fornecimento local (Guerra e Teixeira, 2003).

A quarta rodada, ocorrida em 2002, registrou a maior média de comprometimento local, com $40,5 \%$ na fase de exploração e $56,7 \%$ na de desenvolvimento. Esse fato se explica, entre outras coisas, pela oferta de um grande número de blocos em áreas de menor complexidade e risco geológico.

Percebe-se que, da primeira para a terceira rodada, houve um crescimento significativo do compromisso de aquisição local. Da terceira para a quarta rodada houve um aumento expressivo, exceto em aquisição de suprimentos na fase de exploração de águas profundas, e, na etapa de desenvolvimento em terra, com mais destaque para a primeira que decresceu aproximadamente de $28 \%$ para $20 \%$ na quarta rodada.

Nos quinto e sexto round, o critério foi de mínimo obrigatório, podendo as concessionárias atingir até $100 \%$ de compromisso de aquisição local. Outro fator relevante foi a utilização de percentuais diferenciados para cada local - terra, águas rasas e águas profundas - o que levou ao crescimento ainda maior de compromissos de compras em terra pela maior simplicidade técnica empregada nos produtos. Além disso, o peso para o critério de pontuação, que definiria os vencedores da licitação, passou de $15 \%$ para $40 \%$, ficando o Bônus Assinatura e o PEM com 30\% cada.

A evolução do conteúdo local mínimo, a partir daí, deu-se de forma ascendente e muito além das expectativas. Isso porque não existiu um limite máximo de aquisição, o que gerou uma situação irrealista na sexta rodada, com percentuais de até $100 \%$. Nesse contexto, na sétima rodada, a ANP cogitou, no edital que ficou em Consulta Pública até 30 de junho de 2005, a retirada do percentual de CL como critério de pontuação da licitação como requisito mínimo a ser cumprido. Debates aconteceram entre a ANP, concessionárias, representantes da indústria nacional e MME, em busca da identificação da melhor alternativa para o processo de indução do desenvolvimento da indústria local. Ao fim dos debates, chegou-se a um consenso no que diz respeito a um conteúdo local mínimo capaz de ser atendido de forma competitiva pelas empresas e induziu-se o conceito de conteúdo local máximo, como era feito nas Rodadas 1 a 4 . O objetivo, além de evitar situações irrealistas ocorridas no Round 6, é induzir o aumento da capacidade da indústria nacional de bens e serviços em determinados setores (ANP, 2006).

Além das normas introduzidas nas rodadas de licitações, o estudo feito evidenciou ainda a importância de se criar um organismo de mobilização, articulação e facilitação entre as indústrias do petróleo, o governo e as empresas brasileiras de bens e serviços, para aumentar as compras locais. 
Dessa forma, criou-se, em 1999, a Organização Nacional de Indústria do Petróleo, a Onip, composta por organizações representativas da Indústria de Petróleo e Gás Natural (Marzani, 2004). O seu objetivo é maximizar o conteúdo local no fornecimento de bens e serviços, garantindo ampla igualdade de oportunidades para o fornecedor nacional. A Onip iniciou um novo modelo de interação entre os representantes do setor petrolífero, reunindo fornecedores, concessionários, operadores e organismos públicos e financeiros. Entre seus ramos de atuação estão: a criação e manutenção de ambiente favorável a novos investimentos e operações no Brasil; a atração de produtores de gás, petróleo e derivados e fornecedores de bens e serviços; o fortalecimento da capacidade industrial instalada; a orientação para redução de custos em toda a cadeia produtiva do setor petrolífero; o aumento da competitividade dos fornecedores nacionais de bens e serviços; e a implementação e operacionalização de políticas industriais orientadas para o setor de óleo \& gás (Onip, 2006).

Essa iniciativa estava em sintonia com a nova proposta governamental de aumentar a participação nacional na área petrolífera. Vale ressaltar que a própria ANP já havia decidido aumentar o peso do compromisso de compra de bens e serviços em suas rodadas de licitações.

Um aspecto importante na criação da Onip foi a decisão de que um incentivo às compras no país deveria ser feito a partir do fortalecimento da competitividade da indústria brasileira e não com as reservas de mercado. Dessa forma, foram identificados fatores a serem trabalhados: isonomia tributária, financiamento junto ao BNDES, para dar condições de competitividade às empresas brasileiras sob o aspecto de captação de recursos, tecnologia, recursos humanos e continuidade de encomenda.

Mediante identificação dos pontos acima descritos pela Onip, a ANP adotou uma ação pra estimular o aumento da competitividade junto a outros órgãos governamentais e às próprias empresas. Além da tentativa de isonomia tributária, anteriormente citada , foi adotado como medidas a formação de mão de obra especializada, bem como o provimento de recursos financeiros destinados à capacitação tecnológica.

Mesmo com todas as medidas adotadas pelas ANP e Onip, atender um mercado de proporções econômicas expressivas, como a indústria de petróleo no Brasil, representa um desafio complexo para a indústria de bens e serviços nacional, pois, nesse contexto de profundas mudanças mercadológicas, as empresas nacionais passaram a lidar com diferentes culturas, procedimentos e estratégias. Além disso, havia uma competição com fornecedores estrangeiros altamente qualificados e com ampla experiência no comércio internacional, os quais, como exportadores de bens, beneficiam-se de incentivos fiscais e financeiros oferecidos pelos seus países de origem.

Agregado aos pontos apresentados anteriormente, há dois fatores recorrentes que tornam ainda mais difícil o cenário brasileiro: a legislação tributária e o custo do capital. O regime fiscal vigente para o setor (Repetro), se por um lado encoraja novos investimentos ao desonerá-los deimpostos, de outro, torna o mercado interno completamente livre à concorrência externa, devido à

completa isenção de impostos para produtos importados, sem que o menor grau de isenção seja proporcionado aos produtos locais, sobre os quais ainda incide $o$ ICMS. Mas, como dificuldade maior, ressalta-se o custo financeiro atualmente praticado no Brasil, tanto para investimento como para capital de giro, o que, na prática, anula a competitividade da empresa fornecedora brasileira frente aos concorrentes estrangeiros, os quais têm acesso fácil a créditos com juros próximos de zero (Rappel, 2003).

Nesse processo, a captação de recursos via financiamento é ainda um problema, pois a demora para se obter financiamento tem afetado a modernização das empresas de bens e serviços. O grande desafio do setor continua sendo, portanto, garantir igualdade de condições para que os fornecedores locais possam participar competitivamente dos processos de aquisição de materiais, equipamentos e serviços, demandados pelos projetos em desenvolvimento no país.

Apesar da complexidade do cenário, tem-se visões de futuro otimistas para o setor de petróleo e gás. Segundo as conclusões do estudo realizado pela ANP e PUC-Rio, em 2002, presume-se que as iniciativas dos empresários nacionais encontrariam respaldo em um conjunto de políticas públicas de estímulo ao desenvolvimento de fornecedores locais. Tais políticas englobam: planejamento energético consistente; um aprimoramento do Repetro; estímulos à substituição competitiva de importações; incentivos de financiamento; capacitação e desenvolvimento tecnológico-gerencial; desenvolvimento de redes nacionais e regionais.

A história revela que, desde a quebra do monopólio em 1997, existe o empenho do Poder Público e de entidades privadas, como a Onip, em fortalecer o mercado interno, principalmente, no que se refere ao fornecimento de bens e serviços locais. No entanto, pode-se perceber também que as medidas de maior impacto neste sentido ocorreram, com maior intensidade, nos períodos imediatamente posteriores a 1998. De 1999 até 2003, os programas de incentivo foram profundos e se constituíram no primeiro passo para o desenvolvimento do mercado supridor nacional. De 2003 até o momento atual, esses programas foram continuados, porém o meio de maior destaque desse desenvolvimento é a imposição do Conteúdo Local.

Acostumados ao marasmo do segmento onshore nos últimos anos, as companhias de serviços e equipamentos estão investindo na nova demanda que se apresenta. A retomada de pedidos, aos poucos, começa a dar novos contornos ao mercado, impactando positivamente o faturamento de algumas empresas e retomando a operação de unidades fabris, fechadas, há alguns anos, por falta de contrato. Com a demanda por serviços e materiais maior que a oferta e pressionado pela necessidade de cumprir seus programas de trabalho, há petroleiras novatas fazendo a vez de prestadores e comprando sondas. $\mathrm{O}$ aquecimento do mercado faz surgir os primeiros movimentos de criação de uma indústria nacional de pequeno porte voltada à prestação de serviços e ao fornecimento de equipamentos. Vale salientar que a entrada de novos players está ampliando as chances de novos contratos, reduzindo os riscos das empresas 
de serem fornecedoras de um único cliente.

Nesse novo cenário, alguns analistas defendem que é essencial a diversificação não só das petroleiras, como também do mercado de fornecedores e prestadores de serviços. O surgimento de uma indústria de bens e serviços nacional é de suma importância para garantir o atendimento da demanda dos produtores.

\section{Indução ao fornecimento local - iniciativas e propostas}

Muitas foram as iniciativas criadas para incentivar o fornecimento de bens e serviços para o upstream da indústria do petróleo no Brasil. No entanto, ainda há carência nesse fornecimento, em nível local, principalmente para as empresas independentes de pequeno porte e operadoras de campos marginais. Muitas são as medidas de cunho local que foram tomadas a fim de sanar o problema.

Inicialmente, em 2002, foi criada a Rede Cooperativa em Engenharia de Campos Maduros (RECAM), com incentivo da FINEP. Seu objetivo é realizar pesquisas e projetos direcionados aos campos maduros e marginais da região nordeste, através de parcerias com outras universidades do país. Dentre as universidades que compõem a RECAM estão: Universidade Salvador (UNIFACS), Universidade Federal da Bahia (UFBA), Universidade Federal de Sergipe (UFS), Universidade Federal de Pernambuco (UFPE), Universidade Católica de Pernambuco (UNICAP), Universidade Federal do Rio Grande do Norte (UFRN) e Fundação Instituto Tecnológico do Estado de Pernambuco (ITEP) e também de empresas da indústria do petróleo como a Petrobras, ANP, Bahiagas, Petrorecôncavo, Queiroz Galvão, W. Washington, que atuam no Estado e demais regiões do país.

Em 2003, a ANP firmou um convênio com a UFBA (Universidade Federal da Bahia), transferindo para a Escola Politécnica a propriedade de cinco campos maduros. Os objetivos desse convênio foram a revitalização dos campos, o desenvolvimento de tecnologia para a extração de óleo e gás, o treinamento de pessoal e o aperfeiçoamento do ensino. O Projeto Campo-escola (PCE) foi criado com a responsabilidade de atingir tais metas do convênio.

Em 2006, quando ocorreu a primeira rodada de campos com acumulações marginais, foi criada a APPOM (Associação das Empresas de Petróleo e Gás Natural Extraídos de Campos Marginais do Brasil), com a finalidade de promover e defender a atividade de produção de petróleo e gás natural extraídos de campos marginais. É uma entidade de direito privado, sem fins econômicos, com sede no Município de Salvador, Bahia. A idéia nasceu para que as empresas que adquiriram áreas ofertadas na Primeira Rodada de Campos Marginais se unissem para tornar o negócio mais lucrativo.

Com a união das empresas, alguns investimentos poderão ser feitos em conjunto, o que resolve alguns problemas relacionados ao suprimento de bens e serviços. É possível construir apenas uma estação de tratamento, um ponto de venda e adquirir equipamentos que podem ser revezados entre empresas. A união deve ajudar a abrir espaço para as micro, pequenas e médias empresas e desenvolver uma forte cadeia de fornecedores para o setor de petróleo. Para isso, a Associação está trabalhando para realizar eventos, intensificar a troca de experiências, viabilizar a contratação coletiva de bens e serviços e propiciar ambiente para surgimento de consórcios.

Como exemplo de contratação coletiva, no ano de 2007, a APPOM assinou um contrato de prestação de serviços de sonda de produção terrestre com a empresa baiana Riveti Consultores Associados, para atender as demandas dos programas de trabalhos das empresas a ela associadas. Trata-se de um contrato coletivo com cotas de responsabilidade individuais a ser gerenciado por um comitê gestor que atenderá as empresas associadas da APPOM. A sonda contratada é um equipamento de fabricação nacional novo que foi encomendado pela Riveti no inicio do ano de 2006, baseado em projeto nacional.

Além dessa iniciativa, a APPOM, em consonância com a ANP/PCE, almeja a construção, de forma consorciada com as empresas associadas, de uma mini-refinaria, com a finalidade de tratar o óleo extraído de campos marginais. Isto seria uma forma de solucionar o problema da venda do hidrocarboneto.

Outra iniciativa incentivadora, também criada em 2006, com o apoio do SEBRAE (Serviço de Apoio às Micro e Pequenas Empresas), da Petrobrás e da SECTI (Secretaria de Ciência Tecnologia e Inovação), foi a RedePetro Bahia. De abrangência local, a RedePetro Bahia tem a finalidade de promover a inserção competitiva das micro, pequenas e médias empresas baianas, atuais e potenciais fornecedoras de bens e serviços, à cadeia produtiva de petróleo e gás natural.

A Rede atualmente organiza eventos para a divulgação e promoção das empresas fornecedoras baianas de bens e serviços para a indústria petrolífera, tentando identificar oportunidades de negócios, viabilizar o intercâmbio de informações de interesse geral e adquirir visibilidade em eventos técnicos e força de grupo diante do mercado externo.

A FIEB (Federação das Indústrias do Estado da Bahia), a fim de criar um fórum de discussões formado por empresas, instituições apoiadoras, universidades e demais organismos ligados a indústria de petróleo e gás, deu origem ao Comitê de Petróleo e Gás. Esse Comitê ganhou grande relevância no cenário baiano como propulsor de novas pesquisas e idéias para incentivar o setor. O Comitê se reúne mensalmente para discutir temas e assuntos de interesse da indústria de petróleo e gás. Os resultados dessas reuniões são encaminhados à Presidência da FIEB para ações positivas em prol do crescimento e desenvolvimento desta indústria na Bahia.

A SECTI mantém em sua organização a Coordenação de Cooperação em Redes de Petróleo e Gás, que deu um grande auxílio à RedePetro Bahia e participa das reuniões da Comitê da FIEB, contribuindo com o crescimento e desenvolvimento da indústria de P\&G na Bahia. Além disso, a secretaria prevê a criação de um núcleo de Pesquisa e Desenvolvimento (P\&D) da Petrobras no Parque Tecnológico, em parceria com universidades baianas. A idéia é que esse 
núcleo englobe laboratórios de pesquisa e infra-estrutura, atuando na busca de soluções tecnológicas que agreguem valor à cadeia de petróleo e gás. O Parque Tecnológico está sendo implantado na Avenida Luís Viana Filho, em Salvador, e deverá começar a operar em 2009 (SECTI, 2008).

Em relação às propostas para melhorar as dificuldades no fornecimento local de suprimentos para pequenas e médias operadoras de campos marginais, muitos estudos foram realizados, não somente em âmbito nacional, como também nas esferas do estado da Bahia. Prominp (2006) apresenta uma série de sugestões e estratégias para reestruturar e ampliar os parques supridores regionais, como:

- Criação de empresas locais para a prestação de serviços especializados;

- Instalação de unidades avançadas locais de fornecedores tradicionais da indústria do petróleo, visando à melhoria da assistência técnica pós-venda;

- Parcerias entre universidades e empresas locais para prestação de serviços de elevado conteúdo tecnológico, bem como para a realização de estudos e projetos avançados;

- Formação de pool de fornecedores próximo às áreas de operação;

- Criação de condomínios empresariais em áreas próximas aos campos produtores.

As principais vantagens comparativas para a indústria de petróleo e gás, com a criação de empresas locais para a prestação de serviços especializados, podem ser elucidadas: pela facilidade de acesso a produtos e serviços; pelo emprego de moeda e língua locais; pela mobilidade da assistência técnica e maior comodidade para substituir peças e componentes e pela facilidade de logística e de tempo de entrega. Se o fornecimento local se der de forma eficiente e concorrencial, muito provavelmente, a aquisição de bens e serviços por parte das companhias petrolíferas será naturalmente direcionado para o mercado interno (Onip, 2003).

Para que a inserção dessas empresas no mercado seja possível, a Onip (2003) aponta quatro fatores fundamentais: dimensão do mercado local, capacidade industrial existente, capacitação técnica disponível e políticas governamentais.

$\mathrm{O}$ primeiro fator refere-se à ampliação do segmento de exploração e produção terrestre e aumento da participação de companhias operadoras independentes, sendo crucial a realização de novos leilões de blocos em áreas maduras e de campos marginais.

O segundo fator trata da tradição de fornecimento existente que pode facilitar a constituição ou o aumento da capacidade de um parque fornecedor local, dependendo do crescimento da demanda.

O terceiro fator diz respeito às oportunidades de atuação dos fornecedores regionais para assimilar tecnologias essenciais e, em estreita colaboração com instituições tecnológicas locais, promover o desenvolvimento de novos produtos que atendam às demandas de um conjunto cada vez mais diversificado de novos atores.

Por fim, o quarto fator refere-se à promoção, por parte dos órgãos públicos e ANP, de incentivos à aquisição de bens regionais. Atualmente existem iniciativas nesse sentido, porém de abrangência nacional, como a Cláusula do Conteúdo Local, linhas de créditos facilitadas do BNDES e criação do PROMINP. Na Bahia, o BNB (Banco do Nordeste do Brasil) disponibiliza crédito facilitado para o pequeno fornecedor, o que se pode considerar uma forma de incentivo ao suprimento local de bens e serviços à indústria do petróleo.

Em entrevista ao DCI, em 28 de fevereiro de 2007, o ex-diretor da Onip, Eloi Fernandez y Fernandez, apresenta cinco pontos críticos para elevar a competitividade da indústria brasileira. São eles: a questão tributária, as condições de financiamento, os investimentos em recursos humanos e em tecnologia e a sustentabilidade da demanda. Segundo o ex-diretor, essas questões não são contempladas diretamente no Programa de Aceleração de Crescimento (PAC) ou foram nele incluídos de forma tímida (Nogueira, 2007).

A Instalação de unidades avançadas locais de fornecedores tradicionais da indústria do petróleo e as parcerias entre universidades e empresas locais para prestação de serviços de elevado conteúdo tecnológico, bem como para a realização de estudos e projetos avançados, têm grande potencial no upstream. De acordo com o Prominp (2006), alguns bens e serviços poderiam ser ofertados por empresas de pequeno porte instaladas nas proximidades das operadoras de campos marginais. Seriam eles:

- Serviços - operações de sonolog e dinamômetro, desparafinação de tubos e linhas (desparafinação mecânica e circulação de óleo quente), serviços de oficina mecânica (inspeção, testes, reparos de bombas de fundo de poço), calibração de válvulas de gás lift, etc.), serviços de pipe shop e serviços laboratoriais (determinação de BSW, seleção de desemulsificantes);

- Bens - produtos químicos e reagentes, hastes e componentes para bombeio mecânico, equipamentos de cabeça de poço e medidores de vazão.

Além dos suprimentos que poderiam ser fornecidos por pequenos fornecedores, Prominp (2006) cita alguns serviços que poderiam ser fruto de parcerias entre universidades e instituições tecnológicas locais com empresas de engenharia e de base tecnológica para atender à demanda de serviços especiais de exploração e produção. Estes serviços seriam: serviços de acompanhamento e estudos de reservatório, análise de Testemunhos e Análise PVT, projetos 
Básicos e de Engenharia de Detalhamento, análise da integridade estrutural das instalações de produção e estudos ambientais.

Percebe-se um grande mercado para pequenos fornecedores locais e para a aplicação de $P \& D$ em universidades e centros de pesquisa. A entrada de novas firmas prestadoras de serviços propiciaria a adequação de contratos ao perfil dos pequenos operadores. Dessa forma, a presença dessas novas prestadoras de serviços garantiria a manutenção dos operadores existentes, assim como estimularia novos investidores a adquirirem outros campos marginais na região.

Outra proposta para solucionar o problema do suprimento local seria a formação de pool de fornecedores próximo às áreas de operação e a criação de condomínios empresariais em áreas próximas aos campos produtores. A RedePetro Bahia é um exemplo de formação de pool, porém sem condomínio empresarial.

O pool de fornecedores regionais é um sistema que agrupa empresas de suprimento para a negociação conjunta. Quando se organizam em condomínio, os fornecedores se instalam em áreas com infra-estrutura comum e próximas às unidades operacionais. Com a união, as pequenas e médias empresas podem participar de grandes negócios. Além disso, organizados em pool, os fornecedores poderão encontrar linhas de crédito mais facilitadas para financiar investimentos e capital de giro. Prominp (2006) descreve ainda o papel do gestor do pool e a possível contribuição dos governantes para incentivar a viabilização do pool:

gestor do pool exerce um papel fundamental em sua administração,responsabilizando-sepelalogísticae administração da área condominial, articulação e facilitação do relacionamento com clientes, bem como a promoção do relacionamento com as autoridades públicas. Governos municipais podem contribuir significativamente para a viabilização do pool de fornecedores, na medida em que dêem incentivos fiscais e criem infra-estrutura básica para a instalacão de fornecedores em áreas adequadas (PROMINP, 2006).

A criação do APL (Arranjo Produtivo Local) na região do Recôncavo baiano seria outra proposta de ampliação e manutenção do fornecimento local. Nesse lugar, encontram-se instaladas, atualmente, grande parte dos fornecedores de bens e serviços para o upstream. Isso possibilita a dinamização do arranjo, a partir da adequação de um conjunto de fatores, que incluem a melhoria das condições locais de infra-estrutura, o adensamento da estrutura produtiva e dos relacionamentos inter-industriais subjacentes e a intensificação dos esforços inovativos realizados pelos agentes, particularmente aqueles que envolvem articulações cooperativas que possibilitem uma integração virtuosa de competências complementares (CTPETRO, 2003).

Em relação ao fornecimento de mão de obra local especializada, pode-se

inferir que a estrutura de ensino existente ainda está aquém das necessidades das operadoras. Para solucionar, ou reduzir o problema, é preciso estabelecer mecanismos institucionalizados e ativos, de comunicação entre as instituições de ensino, as empresas operadoras - integração empresa-escola. O obstáculo é conseguir, juntamente com a formação profissional teórica, o ensino prático com estágios em áreas de produção. Uma alternativa seria a ampliação do apoio à capacitação local, por meio da utilização dos recursos do CTPETRO, a partir da referência de novos modelos institucionais de articulação universidade empresa.

Devido ao crescimento da exploração e produção de hidrocarbonetos e da introdução de novas empresas produtoras em campos marginais, éinquestionável a ampliação da demanda local de bens e serviços. Porém, o suprimento de bens, serviços e recursos humanos locais não estão adequadamente estruturados para atender à acentuada expansão de demanda. Assim, medidas de indução ao desenvolvimento do suprimento local devem ser vistas como prioridade.

O poder público pode ser fundamental para o desenvolvimento do suprimento local, criando condições favoráveis à instalação de novas companhias fornecedoras nas regiões petrolíferas. Isso pode ser feito por meio de concessões fiscais e da melhoria na infra-estrutura básica nas áreas industriais.

Além das medidas citadas, é necessária a mobilização de instrumentos que facilitem o acesso de pequenas e médias empresas fornecedoras de tecnologias mais modernas adaptadas às necessidades de campos marginais, geradas por universidades e instituições de pesquisa. Outro mecanismo seria a criação de medidas de apoio tecnológico aos fornecedores, voltadas para a produção em pequena escala, contemplando tecnologias de recuperação terciária, de elevação artificial de reservatórios e de recuperação de áreas de exploração ambientalmente degradadas.

Contudo, vale salientar que a Petrobrás ainda é a grande propulsora do mercado nacional. As empresas fornecedoras nacionais de bens e serviços ainda vislumbram a Companhia como o grande alvo, e possuem, em sua maioria, pouco interesse por outras empresas, principalmente as operadoras de pequeno porte.

\section{Considerações finais}

Considerando o histórico apresentado e as iniciativas e propostas de indução ao fornecimento local de bens, serviços e recursos humanos para o upstream, percebe-se a necessidade de maior esforço de articulação entre os novos produtores, com vistas à ampliação e capacitação do núcleo de fornecedores de materiais, equipamentos e serviços em âmbito local. Vale salientar ainda que os bens e serviços de maior avanço tecnológico não são fornecidos no estado da Bahia.

As iniciativas e propostas para a indução ao fornecimento local estão ganhando forças, com destaque para a criação de associações e órgãos como: a RECAM em 2002, a APPOM em 2006, a RedePetro Bahia no mesmo ano, o Comitê de Petróleo e Gás da FIEB e a Coordenação de Cooperação em Redes de Petróleo e Gás da SECTI. 
A forma de prover o mercado local de suprimentos necessários à ampliação das atividades de exploração e produção de hidrocarbonetos perpassa uma série de mecanismos de incentivo à entrada e manutenção de fornecedores locais. No caso da revitalização de campos marginais por operadoras de pequeno porte, isso é ainda mais necessário. Como forma de alcançar esse objetivo, faz-se necessário a criação de empresas locais para a prestação de serviços especializados; a instalação de unidades avançadas locais de fornecedores tradicionais da indústria do petróleo, visando à melhoria da assistência técnica pós-venda; as parcerias entre universidades e empresas locais para prestação de serviços de elevado conteúdo tecnológico, bem como para a realização de estudos e projetos avançados; e a formação de pool de fornecedores ou condomínios empresariais próximo às áreas de operação.

Existe a necessidade de mobilização de instrumentos que facilitem o acesso, de pequenas e médias empresas fornecedoras, às tecnologias mais modernas, adaptadas às necessidades de campos marginais, geradas por universidades e instituições de pesquisa. Outro mecanismo seria a criação de medidas de apoio tecnológico aos fornecedores, voltadas à produção em pequena escala, contemplando tecnologias de recuperação terciária, de elevação artificial de reservatórios e de recuperação de áreas de exploração ambientalmente degradadas.

Devido ao crescimento da exploração e produção de hidrocarbonetos e da introdução de novas empresas produtoras em campos marginais, é inquestionável a ampliação da oferta local de bens, serviços e mão de obra. O fornecimento local de recursos humanos especializados está aquém das necessidades das operadoras. Para solucionar ou reduzir o problema, deve-se estabelecer mecanismos institucionalizados e ativos, de comunicação entre as instituições de ensino e as empresas operadoras - integração empresa-escola. $\mathrm{O}$ suprimento local de bens e serviços também não está adequadamente estruturado para atender à acentuada expansão de demanda. Assim, medidas de indução ao desenvolvimento do suprimento local devem ser vistas como prioridade.

\section{Referências}

Alvarenga, M.; Fernández, E. (2003). Indústria Nacional de Bens e Serviços. Petro \& Química, São Paulo. Disponível em: <http://www.onip.org.br/main.php?idmain=n oticias\&mainpage=artigos/eloi02.htm>. Acesso em: 13 mar. 2006.

ANP. Portaria n. 279, de 31 de outubro de 2003. Aprova o Procedimento para Cessão Total de Direitos de Campos Marginais. Disponível em: <http://www.anp.gov.br/ doc/petroleo/Proced_Cessao_Campos_Marg.pdf>. Acesso em: 18 nov. 2006.

BNDES (2000). Perspectivas da indústria fornecedora do setor de petróleo. $33 v$. Área de Operações Industriais 2 - AO2, Gerência Setorial de Bens de Capital. Rio De Janeiro.

CTPETRO. (2003). Sistemas produtivos e inovativos locais na indústria de O\&G análise da experiência de campos marginais do recôncavo Baiano. Rio de Janeiro.
DIAGPETRO. (2006). Diagnóstico da cadeia de suprimento dos segmentos de exploração, produção, refino e transporte de petróleo e gás natural. Secretaria de Ciência, Tecnologia e Inovação. Étera Consultoria e Projetos Editoriais, Salvador.

Folkerts, L. K.(2004). A nova indústria nacional de bens e serviços após a flexibilização do monopólio de petróleo. Dissertação (Mestrado) - Regulação da Indústria da Energia, 2004. 220 f. UNIFACS, Salvador.

Furtado, F.; Fernandes, T. (2002). Um bom negócio para pequenos. Ciência Hoje. Rio de Janeiro, v. 32 , n. 188, p. 81-88.

Guerra, O.; Teixeira, F. (2003). A competitividade na cadeia de suprimento da indústria de petróleo no Brasil. Revista de Economia Contemporânea. Rio De Janeiro, n. 72263-288, p.263-287.

Lima, R. C. P. (2006). A cláusula do conteúdo local nos leilões e licitações da ANP como meio de incentivo ao fornecimento local de bens e serviços. In: Congresso Brasileiro de Planejamento Energético. Anais, Brasília: SBPE. p. 31-45.

Marzani, B. S. (2004). Avaliação de Competências dos Fornecedores Locais da Indústria do Petróleo e Gás natural. 2004. 168 f. Dissertação (Mestrado) Politica Cientifica e Tecnologica - Unicamp, São Paulo.

Nogueira, D. Onip vê cinco pontos críticos ao crescimento. Disponível em: <http:// www.inae.com.br/site/index2.php?option=com_content\&do_pdf $=1 \& i d=44>$ Acesso em: 26 nov. 2008.

ONIP. Quem somos. Disponível em: <http://www.onip.org.br/quemsomos/> Acesso em: 20 fev. 2006.

ONIP. (2005). A evolução da política de conteúdo nacional no setor O\&G do Brasil. Rio de Janeiro. Nota Técnica 02/2005.

ONIP. (2003). Incentivo ao fornecimento local de bens e serviços. Rio De Janeiro. Nota Técnica 001/2003.

PROMINP. (2006). Mecanismos de indução à ampliação das atividades de E\&P em áreas terrestres do setor $O \& G$ do Brasil. Relatório do projeto E\&P-15. Rio de Janeiro. Disponível em: < http://www.prominp.com.br> Acesso em: 2 set. 2008.

Rappel, Eduardo (2003). Oportunidades e Desafios do Parque Nacional de Fornecedores de Bens e Serviços para o Setor de Petróleo e Gás. In: Petróleo, royalties e região. Garmond: Rio de Janeiro, 312p.

SECTI. Secretaria de Ciência, Tecnologia e Inovação da Bahia. Parque tecnológico terá núcleo de pesquisa na área de petróleo e gás. Disponível em: $<\mathrm{http}: / /$ www.secti.ba.gov.br/secti/index.php?option=com_content\&view=article\&id $=132 \% 3$ Aparque-tecnologico-tera-nucleo-de-pesquisa-na-area-de-petroleo-egas\&catid=61\%3Aparque-tecnologico\&Itemid=63>. Acesso em: 04 dez. 2008. 
